\title{
Surface binding vs. sequestration; the uptake of benzohydroxamic acid at iron(III) oxide surfaces $\dagger$
}

\author{
Iria M. Rio-Echevarria, ${ }^{a}$ Fraser J. White, ${ }^{a}$ Euan K. Brechin, ${ }^{a}$ Peter A. Tasker ${ }^{*} a$ \\ and Steven G. Harris $* b$
}

Received (in Cambridge, UK) 27th May 2008, Accepted 10th July 2008

First published as an Advance Article on the web 6th August 2008

DOI: $10.1039 / \mathrm{b808805e}$

Benzohydroxamic acid is shown to be an unexpectedly good ligand for iron(III) oxides, favouring surface attachment to the formation of trisbenzohydroxamato complexes, which are known to have very high thermodynamic stability in solution.

The extraordinary stability of tris(hydroxamato)iron(III) complexes has been well documented ${ }^{1,2}$ and underpins the mode of operation of iron transport in vivo by siderophores such as desferrioxamine B. ${ }^{1}$ These siderophores are produced by microorganisms which are very effective in solubilising iron(III) in the environment. ${ }^{2-5}$ Consequently, it is surprising that hydroxamic acids also find application as "collectors" in extractive metallurgy, binding to the surface of iron-containing minerals and rendering them sufficiently hydrophobic to be recovered in froth flotation processes. ${ }^{6-9}$ It would be assumed that dissolution processes such as

$$
\mathrm{Fe}_{2} \mathrm{O}_{3(\mathrm{~s})}+6 \mathrm{LH} \rightleftharpoons 2 \mathrm{FeL}_{3}+3 \mathrm{H}_{2} \mathrm{O}
$$

would be driven by the very high stability of the tris-hydroxamate complexes, $\mathrm{FeL}_{3}$, in solution and that formation of surface complexes would be unfavourable.

As part of a wider programme to develop ligands to "engineer" the properties of metal oxide surfaces we have considered the development of "co-collectors" which would operate in froth flotation processes for sulfide ores to enhance the recovery of ores that have undergone oxidation and present surfaces with significant areas of iron(III) oxides. ${ }^{10}$

In order to identify candidate co-collectors, we assumed that they should have ligating groups with a high affinity for iron(III) oxides, and a screening programme was set up using adsorption isotherm measurements $\ddagger$ to monitor binding strengths to high surface area goethite. The uptake of benzohydroxamic acid from methanol-water (Fig. 1) was followed by the reduction of intensity of the band at $224 \mathrm{~nm}$ in its electronic spectrum. As no iron could be detected in the supernatant solutions by ICP-OES analysis, we can be confident that the steep slope of the isotherm is not a consequence

\footnotetext{
${ }^{a}$ University of Edinburgh, School of Chemistry, West Mains Road, Edinburgh,UK.E-mail: peter.tasker@ed.ac.uk;

Fax: (+44) 131650 6453; Tel: $(+44) 1316504706$

${ }^{b}$ Infineum UK Ltd, PO Box 1, Milton Hill, Abingdon, Oxon,

OX136BB,UK.E-mail: steve.harris@infineum.com;

Fax: (+44) 123546 9371; Tel: (+44) 1235469368

$\dagger$ Electronic supplementary information (ESI) available: Ligand syntheses for $\mathbf{L}^{3}$ and $\mathbf{L}^{4}$. CCDC reference numbers 689505 and 689506. For ESI and crystallographic data in CIF or other electronic format see DOI: $10.1039 / \mathrm{b} 808805$
}

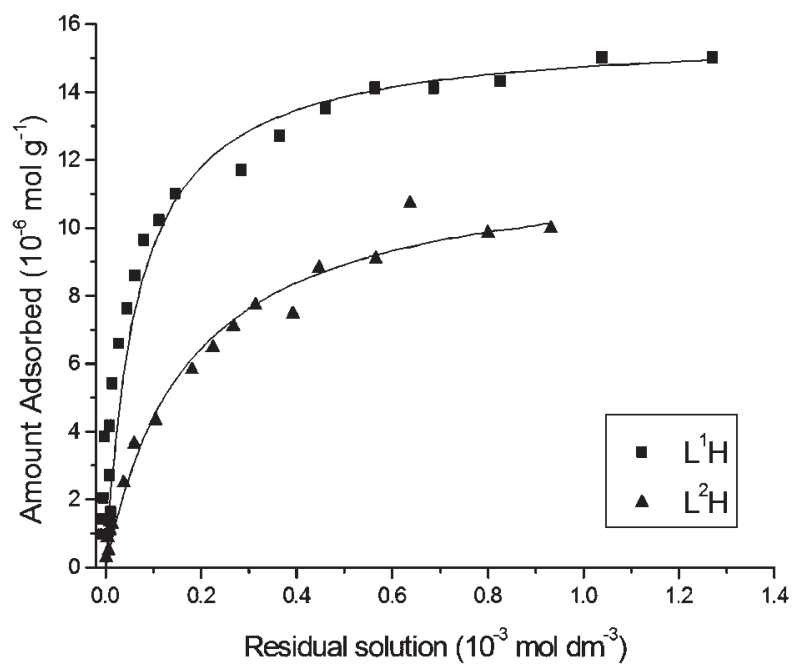

Fig. 1 Uptake of benzohydroxamic acid, $\mathbf{L}^{1} \mathrm{H},(\boldsymbol{\square})$ and 3-(4-methylbenzoyl)propionic acid, $\mathbf{L}^{2} \mathrm{H},(\mathbf{\Delta})$ on high surface area goethite $\left(22.5 \mathrm{~m}^{2} \mathrm{~g}^{-1}\right)$ from $95 \%$ methanol-water.

of the removal of the free ligand to form iron(III) complexes in solution. The binding constant derived from the isotherm shows that benzohydroxamic acid $\left(\mathbf{L}^{\mathbf{1}} \mathrm{H}\right)$ binds more strongly to the surface of goethite than Irgacor $419^{\circledR}$, 3-(4-methylbenzoyl)propionic acid, a waterborne corrosion inhibitor for mild steel. The efficacy of the latter has been ascribed to its ability to show "multisite attachment" to iron(III) oxides, models for which are provided by X-ray crystal structures of polynuclear complexes such as $\left[\mathrm{Fe}_{11} \mathrm{O}_{6}(\mathrm{OH})_{6}\left(\mathbf{L}^{2}\right)_{15}\right] .{ }^{11}$<smiles>[R]c1ccc(C(=O)N([R])[R])cc1</smiles>

$$
\begin{array}{llll} 
& R & R^{1} & R^{2} \\
\mathbf{L}^{1} H & H & H & H \\
\mathbf{L}^{3} \mathrm{H} & \mathrm{H} & \mathrm{Me} & \mathrm{CH}_{2} \mathrm{SC}_{3} \mathrm{H}_{7} \\
\mathbf{L}^{4} \mathrm{H} & \mathrm{Me} & \mathrm{H} & \mathrm{CH}_{2} \mathrm{SC}_{3} \mathrm{H}_{7}
\end{array}
$$<smiles>Cc1ccc(C(=O)CCC(=O)O)cc1</smiles>

There are no comparable structures of polynuclear iron(III) complexes of hydroxamic acids recorded in the CSD, although it has been shown that a deprotonated form of the $\mathrm{NOH}$ group can form bridged copper and manganese complexes. ${ }^{12}$ Our initial attempts to prepare $\mathrm{Fe}^{\mathrm{III}}$ complexes of 
benzohydroxamic acid resulted in mononuclear complexes $\left[\mathrm{Fe}\left(\mathbf{L}^{\mathbf{1}}\right)_{3}\right] . \S$ Both the mer- and fac- forms were present in crystals of $\left[\mathrm{Fe}\left(\mathbf{L}^{\mathbf{1}}\right)_{3}\right] \cdot 1.5 \mathrm{MeOH}$. The geometries of their coordination spheres are similar and correspond closely to those of reported trishydroxamatoiron(III) structures. $^{13} \mathrm{~A}$ dinuclear complex, $\boldsymbol{\top}\left[\mathrm{Fe}_{2}\left(\mu_{2}-\mathbf{L}^{\mathbf{1}}\right)_{2}\left(\mathbf{L}^{\mathbf{1}}\right)_{2} \mathrm{Br}_{2}\right]$, $\S$ separated as almost black crystals from the recrystallization of a purple product arising from the reaction of $\mathrm{FeBr}_{2}, \mathbf{L}^{\mathbf{1}} \mathrm{H}$ and benzoic acid. $\S$ In this centrosymmetric complex (Fig. 2) the bridging benzohydroxamate ligands form bonds of approximately equal lengths from their oximato oxygen atom, O1, to the two iron atoms, and formation of these bridges does not greatly change the geometry of the chelate ring. $\|$

The implication that a dinucleating/bridging mode such as that in $\left[\mathrm{Fe}_{2}\left(\mu_{2}-\mathbf{L}^{\mathbf{1}}\right)_{2}\left(\mathbf{L}^{\mathbf{1}}\right)_{2} \mathrm{Br}_{2}\right]$ can be provided by a relatively strain-free form of a benzohydroxamate ligand when complexed to an oxide surface was tested by modelling the docking of the $\mathrm{Fe}_{2}\left(\mu_{2}-\mathbf{L}^{\mathbf{1}}\right)$ motif onto iron(III) oxy/hydroxides. The (110) surface of lepidocrocite was chosen initially for these studies on the grounds that it contains $\mathrm{Fe}_{2} \mathrm{O}_{2}$ units with similar geometry (Fe. . Fe: 3.060 and O - . O: $2.740 \AA$ A, O-Fe-O: 83.5 and Fe-O-Fe: $\left.91.6^{\circ}\right)$ to those in a range of other iron(III) oxide/hydroxides and is one of the dominant faces of crystals of the mineral.

In Fig. 3 the bridging benzohydroxamate unit in the crystal structure of $\left[\mathrm{Fe}_{2}\left(\mu_{2}-\mathbf{L}^{\mathbf{1}}\right)_{2}\left(\mathbf{L}^{\mathbf{1}}\right)_{2} \mathrm{Br}_{2}\right]$ has been used to replace a terminal and an adjacent $\mu_{2}$-bridging hydroxyl group on the

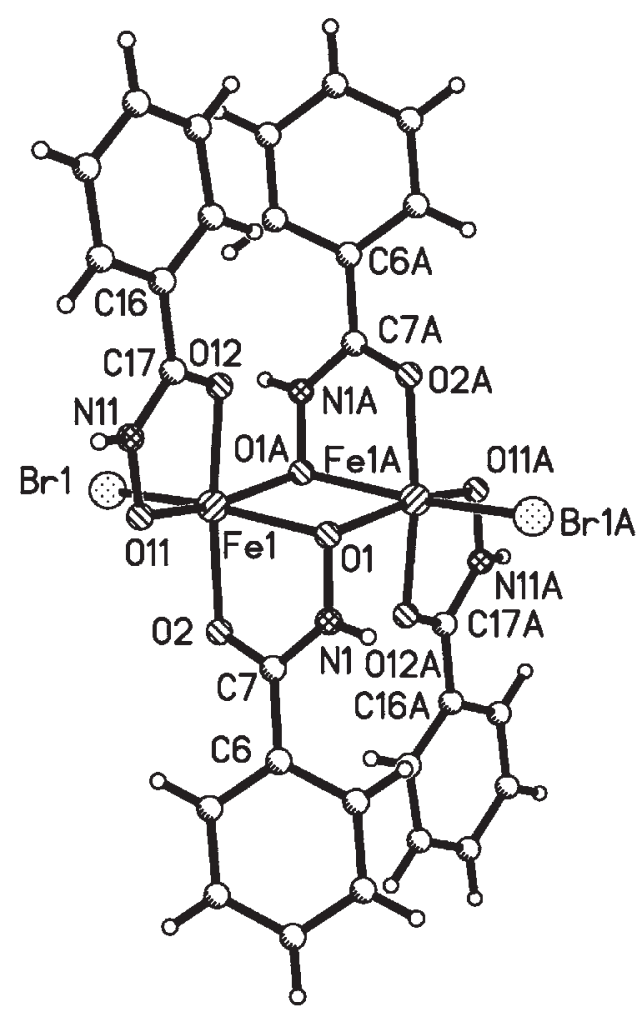

Fig. 2 The structure of $\left[\mathrm{Fe}_{2}\left(\mu_{2}-\mathbf{L}^{\mathbf{1}}\right)_{2}\left(\mathbf{L}^{\mathbf{1}}\right)_{2} \mathrm{Br}_{2}\right]$. Coordination sphere bond lengths are: Fe1-O1: 2.087(2); Fe1-O1A: 2.093(1); Fe1-O2: 2.015(1); Fe1-O11: 1.955(1); Fe1-O12: 2.017(1) and Fe1-Br1: 2.4448(4) $\AA$. Contact distances and angles in the central $\mathrm{Fe}_{2} \mathrm{O}_{2}$ unit

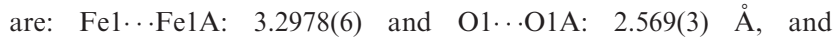
Fe1-O1-Fe1A: 104.16(6) and O1-Fe1-O1A: 75.84(6) ${ }^{\circ}$

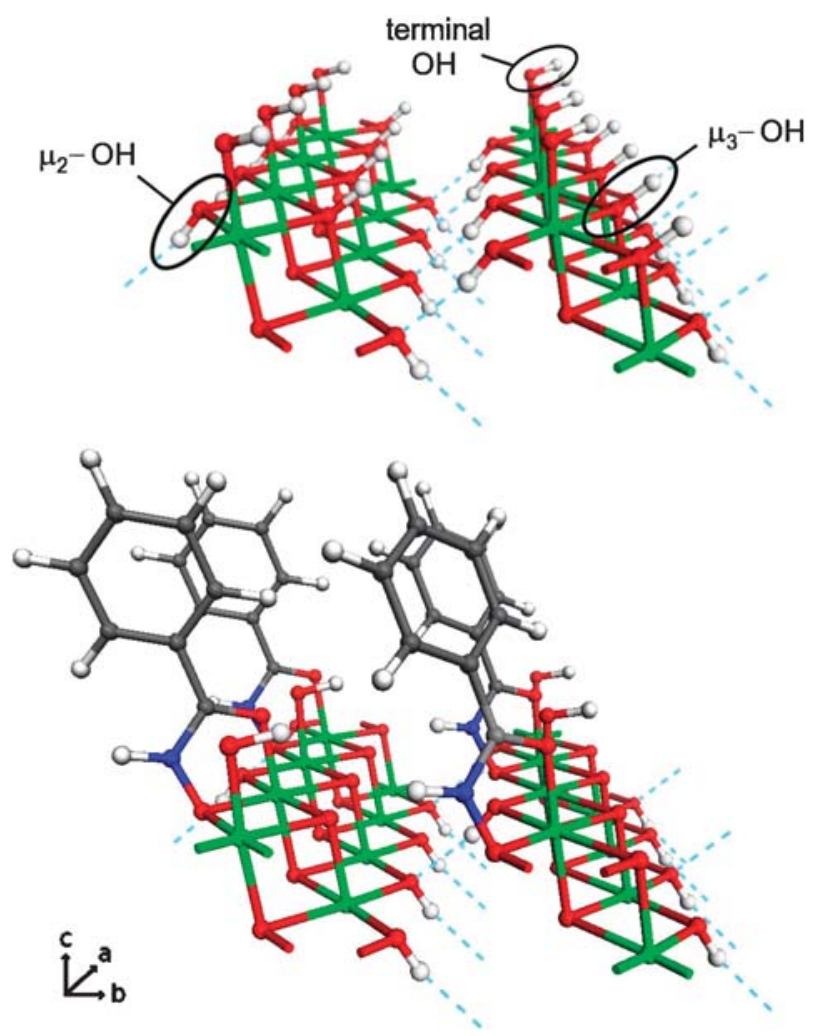

Fig. 3 Two unit cells in the $a$ direction showing the topmost layer of oxide with two benzohydroxamate molecules per unit cell. In order to bind, the hydroxamate displaces both a terminal hydroxide and a $\mu_{2}$ hydroxide. In order to preserve charge balance, the $\mu_{3}$ hydroxides on the right hand side of the binding site are deprotonated, leaving $\mu_{3}$ oxides.

surface. The geometry of the ligand was then optimised using the $\mathrm{UFF}^{14}$ with partial atomic charges derived by charge equilibration, ${ }^{15}$ whilst keeping the iron and the other oxygen atom positions in the substrate fixed. Bond lengths and angles associated with the ligand in the energy-minimised structures of the surface complex compare well with those in $\left[\mathrm{Fe}_{2}\left(\mu_{2^{-}}\right.\right.$ $\left.\left.\mathbf{L}^{\mathbf{1}}\right)_{2}\left(\mathbf{L}^{\mathbf{1}}\right)_{2} \mathrm{Br}_{2}\right]$. The minimized energy of the chelate unit in the surface structure is higher $\left(16 \mathrm{~kJ} \mathrm{~mol}^{-1}\right)$ than that in the dinuclear complex, but this might be expected because the surface structure was not allowed to relax from that of bulk lepidocrocite to meet the requirements of the hydroxamate ligand. The surface area required per ligand in the model, $38.25 \AA^{2}$, is significantly smaller than that observed for saturation in the isotherm, 240(12) $\AA^{2}$. A similar difference (45 vs. 238(15) $\AA^{2}$ ) was observed in modelling the uptake of the commercial corrosion inhibitor $\mathbf{L}^{2} \mathrm{H}$ on goethite for which a different surface binding motif is proposed. ${ }^{16}$ In both cases this most probably arises because only $c a .18 \%$ of the (110) type binding sites are accessible in the goethite used in the isotherm determination. There are no significant intermolecular contacts between benzohydroxamate ligands in adjacent sites in the model shown in Fig. 3. However, if an N-methyl substituent is introduced, as in $\mathbf{L}^{3} \mathbf{H}$, this is would be expected to lead to steric interactions between ligands. The isotherm for this ligand showed both weaker binding and reduced surface coverage. Replacing the hydroxyl group in $\mathbf{L}^{\mathbf{1}} \mathrm{H}$ with a methoxy group $\left(\mathbf{L}^{\mathbf{4}} \mathrm{H}\right)$ will prevent the formation of hydroxamato 
bridges between $\mathrm{Fe}^{\mathrm{III}}$ atoms and, as expected, no uptake of $\mathbf{L}^{4} \mathrm{H}$ onto goethite was detected.

Despite the well defined propensity to form very stable mononuclear iron(III) complexes, it is clear that simple hydroxamic acids can also bind sufficiently strongly to the surfaces of iron(III) oxides that dissolution of iron to tris-hydroximato complexes is not the favoured reaction. This observation has relevance to the modes of action of hydroxamate-containing siderophores in their role of scavenging for iron from solid materials and also for the stabilisation of colloidal iron(III) oxyhydroxides. It is also possible that the efficacy of benzohydroxamic acid as a collector in flotation processes could depend on the formation of very stable complexes with oxidized pyrite on the surface of sulfide minerals.

We thank the EPSRC and Rio Tinto and Infineum for CASE studentships, EaStCHEM for funding and Dr D. Nagaraj (Cytec Industries) and Drs Chris Cross and Lucy Esdaile (Rio Tinto) for very helpful discussions.

\section{Notes and references}

$\ddagger$ Different concentrations of each benzohydroxamic acid in methanol-water $(10 \mathrm{ml}, 95: 5 \mathrm{v} / \mathrm{v})$ were added to accurately weighed samples (ca. $0.40 \mathrm{~g})$ of high surface area $\left(22.5 \mathrm{~m}^{2} \mathrm{~g}^{-1}\right)$ goethite in polycarbonate centrifuge tubes. The suspensions were stirred for $2 \mathrm{~h}$ at $25{ }^{\circ} \mathrm{C}$ and then centrifuged. Aliquots of the supernatant solutions were filtered through glass microfibre filter paper, which was then washed $(3 \times 0.5 \mathrm{ml})$ with methanol-water $(95: 5 \mathrm{v} / \mathrm{v})$ and the combined filtrate and washings made up to volume. For $\mathbf{L}^{1}$ the absorbance at $224 \mathrm{~nm}$, and for $\mathbf{L}^{3}$ and $\mathbf{L}^{4}$ the sulfur-content measured by ICP-OES, were used to determine the concentration of ligand remaining in solution. For $\mathbf{L}^{1}$ the adsorption constant and surface coverage are $16(3) \times 10^{3}$ and $15.5(8) \times 10^{-6} \mathrm{~mol} \mathrm{~g}^{-1}$. A double Langmuir equation was needed to fit isotherm data for $\mathbf{L}^{3}$.

$\S$ The complex $\left[\mathrm{Fe}_{2}\left(\mu_{2}-\mathbf{L}^{\mathbf{1}}\right)_{2}\left(\mathbf{L}^{\mathbf{1}}\right)_{2} \mathrm{Br}_{2}\right]$ was synthesised by dissolving in methanol equimolar amounts of $\mathrm{FeBr}_{2}(0.300 \mathrm{~g}, 1.39 \mathrm{mmol})$, $\mathrm{NaOOCPh}(0.200 \mathrm{~g}, 1.39 \mathrm{mmol})$ and benzohydroxamic acid $(0.191 \mathrm{~g}$, $1.39 \mathrm{mmol}$ ). The resulting purple solution was stirred overnight at room temperature, after which a purple precipitate was obtained and removed by filtration. Layering of the filtrate with diethyl ether gave black crystals of $\left[\mathrm{Fe}_{2}\left(\mu_{2}-\mathbf{L}^{\mathbf{1}}\right)_{2}\left(\mathbf{L}^{\mathbf{1}}\right)_{2} \mathrm{Br}_{2}\right]$ after 4 weeks. Yield $5 \%$. (Found: C, 41.26; $\mathrm{H}, 3.04 ; \mathrm{N}, 6.78$. Calc. for $\mathrm{C}_{28} \mathrm{H}_{24} \mathrm{Br}_{2} \mathrm{Fe}_{2} \mathrm{~N}_{4} \mathrm{O}_{8}$ : C, 41.21; H, 2.96; N, 6.87). $\nu_{\max } / \mathrm{cm}^{-1} 1596(\mathrm{C}=\mathrm{O}), 555(\mathrm{Fe}-\mathrm{O})$.

- Crystal data for $\left[\mathbf{F e}_{2}\left(\mu_{2}-\mathbf{L}^{1}\right)_{2}\left(\mathbf{L}^{\mathbf{1}}\right)_{2} \mathbf{B r}_{2}\right] \cdot \mathrm{C}_{28} \mathrm{H}_{24} \mathrm{Br}_{2} \mathrm{~N}_{4} \mathrm{O}_{8} \mathrm{Fe}_{8}, M=$ 816.01, monoclinic, $a=14.5538(9), b=18.2543(10), c=$ 12.9684(8) $\AA, \beta=91.814(4)^{\circ}, V=3066.3(3) \AA^{3}, T=150 \mathrm{~K}$, space group $C 2 / c$ (no. 15), $Z=4,43236$ reflections measured, 4680 unique $\left(R_{\mathrm{int}}=0.0422\right)$ which were used in all calculations. The final $w R\left(\mathrm{~F}_{2}\right)$ was 0.0338 (3511 data). Crystal data for $\left[\mathbf{F e}\left(\mathbf{L}^{\mathbf{1}}\right)_{3}\right] \cdot \mathbf{1 . 5} \mathbf{M e O H}$. $\mathrm{C}_{45} \mathrm{H}_{48} \mathrm{~N}_{6} \mathrm{O}_{15} \mathrm{Fe}_{2}, M=1024.59$, monoclinic, $a=20.2477(8), b=$ 11.3483(4), $c=22.4035(9) \AA, \beta=115.874(2)^{\circ}, V=4631.8(3) \AA^{3}$, $T=150 \mathrm{~K}$, space group $P 2_{1} / c$ (no. 14 ), $Z=4,62262$ reflections measured, 10127 unique $\left(R_{\text {int }}=0.0442\right)$ which were used in all calculations. The final $w R\left(F_{2}\right)$ was 0.0371 (8129 data).

$\|$ The bite angle, $\mathrm{O} 1-\mathrm{Fe}-\mathrm{O} 2 ; 76.74(5)^{\circ}$ and the carbonylato oxygento-iron bond length, O2-Fe; 2.0151(13) $\AA$, are similar to those in the non-bridging chelate ring and to the mean values in the mononuclear complexes $\left[\mathrm{Fe}\left(\mathbf{L}^{\mathbf{1}}\right)_{3}\right], 79.69(5)^{\circ}$ and $2.0167(14) \AA$, and $78.67^{\circ}$ and $2.037 \AA$ A, respectively.

1 C. J. Marmion, D. Griffith and K. B. Nolan, Eur. J. Inorg. Chem., 2004, 3003-3016.

2 R. J. Bergeron, J. Wiegand, J. S. McManis, W. R. Weimar and G. Huang, in Adv. Exp. Med. Biol., CRC, Boca Raton, 2002, pp. $167-184$.

3 K. J. Wallace, M. Gray, Z. Zhong, V. M. Lynch and E. V. Anslyn, Dalton Trans., 2005, 2436-2441.

4 W. R. Harris, C. J. Carrano, S. R. Cooper, S. R. Sofen, A. E. Avdeef, J. V. McArdle and K. N. Raymond, J. Am. Chem. Soc., 1979, 101, 6097-6104.

5 M. Gaspar, R. Grazina, A. Bodor, E. Farkas and M. A. Santos, J. Chem. Soc., Dalton Trans., 1999, 799-806.

6 D. W. Fuerstenau, Proceedings of the 19th International Mineral Processing Congress, San Francisco, 1995, vol. 3, pp. 3-17.

7 D. R. Nagaraj, Trans. Indian Inst. Met., 1997, 50, 355-363.

8 Mining Chemicals Handbook, Cytec Industries Inc., New Jersey, 2002.

9 K. K. Das and Pradip, Process Technol. Proc., 1988, 7, 305-316.

10 I. M. Rio Echevarria, PhD Thesis, University of Edinburgh, 2007.

11 M. Frey, S. G. Harris, J. M. Holmes, D. A. Nation, S. Parsons, P. A. Tasker, S. J. Teat and R. E. P. Winpenny, Angew. Chem., Int. Ed., 1998, 37, 3245-3248.

12 CSD Copper Refcodes: LOPBAT; MEMDUD; MEMFAL; MIHMOF; QOFJOK; QOFJUQ; REXTIY; SUGMIQ; VIJRUB; WUTGIX; WUTCOD; YELTAK; YELTEO; YELTIS; YELTOY. Manganese Refcodes: FILFOW; FILGAJ; FIPTAA; HUHPIJ; IDUYOV; IDUYUB; SEDBOS; UMIQUC; YOBYUJ; YOBZEU; YOBZEW.

13 CSD Refcodes: BURDIB; FEBOAH; FEBOAH01; FEBOAH02; SISSAO; SISSES; SUXREI.

14 A. K. Rappe, C. J. Casewit, K. S. Colwell, W. A. Goddard-III and W. M. Skiff, J. Am. Chem. Soc., 1992, 114, 10024-10035.

15 A. K. Rappe and W. A. Goddard-III, J. Phys. Chem., 1991, 95, 3358-3363.

16 M. Frey, S. G. Harris, J. M. Holmes, D. A. Nation, S. Parsons, P. A. Tasker and R. E. Winpenny, Chem.-Eur. J., 2000, 6, $1407-1415$. 